\title{
Aktualisasi Nilai-Nilai Kepemimpinan Astha Brata Untuk Mewujudukan Profil Pelajar Pancasila Melalui Sekolah Penggerak
}

\author{
Atik Dwi Kurniasih \\ Universitas Sebelas Maret \\ atikdk@student.unc.ac.id
}

\section{Article History}

received $1 / 9 / 2021$

\begin{abstract}
To realize the Pancasila Student Profile, the Ministry of Education and Culture, Research and Technology issued one of the Independent Learning Program policies, namely the "Sekolah Penggerak". "Sekolah Penggerak" is implemented by strengthening the capacity roles of principals and driving teachers. The principal is a learning leader in each academic unit who is expected to move the school by collaborating with stakeholders to realize a student-centred school. "Guru Penggerak" are learning leaders who apply independent learning and move the entire educational ecosystem to realize learner-centred education. Becoming a learning leader as a "Sekolah Penggerak" Principal or "Guru Penggerak" requires a new paradigm shift. There is one Javanese local wisdom that can be actualized as a leadership model, namely Astha Brata. This research is a descriptive study by examining the actualization of Astha Brata 's leadership to realize the Pancasila Student Profile in the "Sekolah Penggerak". The method used is literature study through books, journals related documents and news/online. Study results show that Astha Brata 's leadership values are still relevant and can be actualized to answer the challenges of being a school principal and "Guru Penggerak", who is expected to become a learning leader to realize the Pancasila Student Profile.
\end{abstract}

Keywords: Astha Brata, Pancasila Student Profile, Sekolah Penggerak, Actualization

\begin{abstract}
Abstrak
Untuk mewujudkan Profil Pelajar Pancasila Kemendikbud Ristek mengeluarkan salah satu kebijakan Program Merdeka Belajar yaitu Program Sekolah Penggerak. Program Sekolah Penggerak dilaksanakan dengan penguatan peran kapasistas kepala sekolah dan guru. Kepala sekolah merupakan pemimpin pembelajaran pada setiap satuan pendidikan yang diharapkan dapat menggerakan sekolah dengan berkolaborasi bersama permangku kepentingan untuk mewujudkan sekloah yang berpusat pada peserta didik. Guru Penggerak adalah pemimpin pembelajaran yang menerapkan merdeka belajar dan mampu menggerakan seluruh ekosistem pendidikan untuk mewujudkan pendidikan yang berpusat pada peserta didik. Menjadi pemimpin pembelajaran sebagai Kepala Sekolah Penggerak maupun Guru Penggerak diperlukan perubahan paradigma baru, untuk mewujudkan hal tersebut terdapat salah satu kearifan lokal Jawa yang bisa diaktualisasikan sebagai model kepemimpinan yaitu Astha Brata. Penelitian ini merupakan penelitian diskriptif dengan menelaah aktualisasi kepemimpinan Astha Brata untuk mewujudkan Profil Pelajar Pancasila dalam Sekolah Penggerak. Metode yang digunakan yaitu studi literatur melalui buku, jurnal serta dokumen terkait dan juga berita/ online. Hasil penelitian menunjukkan nilai-nilai kepemimpinan Astha Brata masih relevan dan dapat diaktualisasikan untuk menjawab tantangan sebagai Kepala Sekolah serta Guru Penggerak yang diharapkan dapat menjadi pemimpin pembelajaran untuk mewujudkan Profil Pelajar Pancasila.
\end{abstract}

Kata kunci: Astha Brata, Profil Pelajar Pancasila, Sekolah Penggerak, Aktualisasi

Social, Humanities, and Education Studies (SHEs): Conference Series https://jurnal.uns.ac.id/shes

p-ISSN 2620-9284 e-ISSN 2620-9292 


\section{PENDAHULUAN}

Bangsa Indonesia saat ini dihadapkan pada tantangan eksternal berupa hadirnya era revolusi industri 4.0 dan era society 5.0. Era revolusi industri 4.0 bertumpu pada cyber-physical system, dengan didukung oleh kemajuan teknologi, basis informasi, pengetahuan, inovasi, dan jejaring, yang menandai era penegasan munculnya abad kreatif. Sedangkan era zociety 5.0 berfokus pada pengaplikasian teknologi digital pada kehidupan manusia dimana harus lebih mempersiapkan sunber daya manusia yang tepat sebagai penetralisir atas tantangan yang diberikan dari revolusi industri 4.0 yang telah melahirkan berbagai inovasi dan industrialisasi.

Tantangan yang bersifat internal, berupa gejala melemahnya mentalitas anakanak bangsa sebagai dampak maraknya simpul informasi dari media sosial, perubahan gaya hidup modern terutama bagi sebagian remaja saat ini sebagai akibat dari adanya disrupsi pada teknologi, sosiokultural dan lingkungan. Disrupsi pada teknologi membuat sektor lainnya juga berdampak, seperti dengan munculnya era otomatisasi, big data, percetakan 3D hingga kecerdasan buatan dampak dalam sektor sosiokultural yang membuat perubahan demografi, sosio-ekonomi serta kesadaran akan etika, privasi dan kesehatan

Menghadapi tantangan itu semua tentu harus diimbangi dengan pendidikan yang bermutu supaya dapat menjamin tumbuh kembangnya sumber daya manusia yang berkualitas, bisa bertindak cepat, tepat, dan mampu beradaptasi dengan baik dalam mengantisipasi sekaligus mengatasi dampak negatif dari gelombang perubahan tersebut. Kementerian Pendidikan, Kebudayaan, Riset dan Teknologi (Kemendikbudristek) yang paling bertanggung jawab dalam sektor pendidikan nasional dan berperan penting dalam mewujudkan kualitas sumberdaya manusia Indonesia, menindaklanjutinya dengan mengeluarkan berbagai kebijakan penting, diantaranya kebijakan pendidikan "Merdeka Belajar", yang digulirkan oleh Mendikbud Nadiem Anwar Makarim. Diantara konsep pendidikan Merdeka Belajar salah satunya yaitu dengan membuat kurikulum Pendidikan yang berbasis Pancasila yang diberi nama Profil Pelajar Pancasila.

Pembentukan kurikulum Pendidikan berbasis Pancasila merupakan salah satu upaya Kemendikbudristek untuk meningkatkan kualitas Pendidikan di Indonesia demi mendukung terealisasinya penegetahuan dan pembentukan karakter. Tujuan tersebut sangat penting untuk dicapai mengingat dampak dan kekuatiran Kemendikbudristek atas fenomena dari adanya revolusi industri 4.0. (Hasudungan dan Abidin 2020) Untuk mewujudkan tujuan tersebut serta menciptakan SDM unggul serta profil Pelajar Pancasila maka Kemendikbudristek mengeluarkan kebijakan adanya Sekolah Penggerak.

Program Sekolah Penggerak nantinya akan berfokus pada pengembangan siswa secara holistik yang mencakup kompetensi literasi dan numerasi serta karakter yang diawali dengan adanya sumber daya manusia yang unggul dalam hal ini adalah kepala sekolah. Sekolah penggerak mempunyai karakteristik dimana kepala sekokah mempunyai kepemimpinan yang diharapkan mampu untuk menggerakan seluruh anggota satuan pendidkan untuk dapat meningkatkan kualitas belajar siswa (instructional leadership) (Dikmen 2020).

Berdasarkan hal tersebut maka penulis tertarik untuk melakukan suatu analisis terkait aktualisasi kepemimpinan dengan kearifan lokal yaitu Astha Brata untuk mewujudkan profil pelajar pancasila melalui kepemimpinan kepala sekolah pada sekolah penggerak. 


\section{Konsep Profil Pelajar Pancasila}

\section{KAJIAN TEORI}

Mengacu pada Keputusan Menteri Pendidikan, Kebudayaan, Riset dan Teknologi Nomor 162/M/2021 tentang Sekolah Penggerak maka pengertian Profil Pelajar Pancasila adalah profil lulusan yang bertujuan menunjukkan karakter dan kompetensi yang diharapkan diraih dan menguatkan nilai-nilai luhur Pancasila peserta didik dan para pemangku kepentingan. Pelajar Pancasila berpusat pada upaya mewujudkan Pelajar Pancasila yang dimulai dari jenjang pendidikan dasar hingga pendidikan tinggi. Pelajar Pancasila memiliki enam ciri utama, yaitu, beriman, bertakwa kepada Tuhan Yang Maha Esa dan berakhlak mulia, berkebinekaan global, mandiri bergotong royong, bernalar kritis dan kreatif. Untuk itu, dibutuhkan suatu mekanisme atau gerakan penumbuhan karakter, di antaranya melalui sosialisasi, penyempurnaan pembelajaran, dan aneka kompetisi, sehingga profil Pelajar Pancasila dapat terwujud.

1) Beriman, bertakwa kepada Tuhan Yang Maha Esa dan berakhlak mulia Pelajar Indonesia yang menghayati keberadaan Tuhan dan selalu berupaya mentaati perintah serta menjauhi larangan sesuai dengan ajaran agama dan kepercayaan yang dianutnya.

2) Berkebinekaan Global

Pelajar Indonesia yang berkebinekaan global memiliki identitas diri yang matang, mampu menunjukan dirinya sebagai representasi budaya luhur bangsanya, sekaligus memiliki wawasan serta keterbukaan tentang eksistensi ragam budaya daerah, nasional dan global. Pelajar Indonesia memiliki sikap menghormati keberagaman dan toleransi terhadap perbedaan.

3) Mandiri

Pelajar Indonesia memiliki prakarsa atas pengembangan dirinya yang tercermin dalam kemampuan untuk bertanggung jawab, memiliki rencana strategis, melakukan tindakan dan merefleksikan proses dan hasil pengalamannya.

4) Bergotong royong

Pelajar Indonesia memiliki kemampuan untuk melakukan kolaborasi dengan sukarela agar kegiatan yang dikerjakan dapat berjalan lancar dan mencapai tujuan untuk kebaikan bersama.

5) Bernalar kritis

Pelajar Indonesia yang bernalar kritis berpikir secara objektif, sistematik dan saintifik dengan mempertimbangkan berbagai aspek berdasarkan data dan fakta yang mendukung, sehingga dapat membuat keputusan yang tepat dan berkontribusi memecahkan masalah dalam kehidupan, serta terbuka dengan penemuan baru.

6) Kreatif

Pelajar Indonesia mampu memodifikasi dan menghasilkan sesuatu yang orisinal, bermakna, bermanfaat, dan berdampak, dalam bentuk gagasan, tindakan, dan karya nyata secara proaktif dan independen untuk menemukan cara-cara lain dan berbeda untuk bisa berinovasi.

Profil Pelajar Pancasila merupakan upaya menerjemahkan tujuan dan visi pendidikan ke dalam format yang lebih mudah dipahami oleh seluruh pemangku kepentingan pendidikan. Rumusan Profil Pelajar Pancasila dibuat dengan tujuan sebagai kompas bagi pendidik dan Pelajar Indonesia. Segala pembelajaran, program, dan kegiatan di satuan pendidikan bertujuan akhir ke Profil Pelajar Pancasila. (Kemdikbud, 2021).

\section{Konsep Sekolah Penggerak}

Seperti yang tertuang dalam Keputusan Menteri Pendidikan, Kebudayaan, Riset dan Teknologi Nomor 162/M/2021 tentang Sekolah Penggerak, Kementrian Pendidikan, Kebudayaan, Riset dan Teknologi (Kemendikbudristek) adalah pihak yang paling bertanggung jawab dalam upaya melanjutkan dan mengembangkan kebijakan 
peningkatan dan pemerataan mutu pendidikan salah satunya melalui program Sekolah Penggerak. Program Sekolah Penggerak berupaya mendorong satuan pendidikan untuk melakukan trasnformasi diri guna meningkatkan mutu pembelajaran di sekolah untuk selanjutnya melakukan pengimbasan ke sekolah lain dengan tujuan melakukan peningkatan mutu yang serupa.

Sekolah Penggerak adalah sekolah yang berfokus pada pengembangan hasil belajar siswa secara holistik yaitu dengan mewujudkan Profil Pelajar Pancasila yang mencakup kompetensi dan karakter yang diawali dengan sumber daya manusia yang unggul yaitu kepala sekolah dan guru, termasuk didalmnya adalah penguatan kapasitas kepala sekolah dan guru tentang kepemimpinan terutama dalam hal kepemimpinan pendidikan yang berorientasi pada kepemimpinan instruksional.

\section{Konsep Kepemimpinan Astha Brata}

Kepemimpinan adalah kemampuan untuk menggerakan sumber daya yang ada pada organisasi, sehingga dapat didayagunakan secara maksimal guna mencapai tujuan yang telah ditetapkan (Abbas 2014).

Menurut Asri Sundari (2015) konsep kepemimpinan Astha Brata merupakan salah satu konsep kepemimpinan yang bersumber dari kearifan lokal dalam kepmimpinan Jawa yang cukup banyak diapresiasi. Menurut konsep ini seorang pemimpin harus meniru delapan sifat alam yaitu sebagai berikut:

1. Bumi

Bumi mempunyai watak ajeg atau tetap. Pemimpin berdasarkan sifat ini harus tegas, konstan serta konsisten. Bumi juga membawa kesejahteraan bagi selurug makhluk hidup oleh karena itu pemimpin juga harus konsisten memikirkan kesejahteraan anak buahnya.

2. Matahari

Pemimpin menurut sifat ini harus mampu memberi semangat dan membangkitkan motivasi.

3. Bulan

Bulan memberikan penerangan pada saat gelap maka pemimpin harus mampu memberi solusi saat ada masalah serta dapat menjadi penengah pada saat terjadi konflik.

4. Bintang

Seperti sifat bintang yang bisa digunakan sebagai penunjuk arah maka pemimpin harus dapat menjadi panutan serta suri tauladan.

5. Api

Pemimpin menurut sifat api yang membakar harus mampu memhadapi resiko agar dapat membantu kelangsungan hidup organisasi yang dipimpinnya.

6. Angin

Menurut sifat angin yang dapat bergerak ringan dimana saja dan dapat ke mana saja maka seroang pemimpin harus bisa berada dimana saja ketika dibutuhkan anak buahnya serta tidak pernah lelah bergerak dalam mengawasi anak buahnya.

7. Laut atau Samudra

Laut atu samudra merupakan tempat yang luas dan lapang sekaligus menjadi muara aliran sungai. Sebagai seorang pemimpin yang mempunya sifat ini maka hendaknya bersfiat lapang dada dalam menerima banyak masalah.

8. Air

Seperti sifat air yang dapat menyesuaikan tempat dia berada, dapat mengalir sampai jauh dari tempat yang tinggi ke tempat rendah serta dapat menyucikan maka seorang pemimpin harus dapat menyesuaikan diri, merendahkan diri serta dapat mengerti situasi dan kondisi. 


\section{METODE}

Jenis penelitian yang digunakan adalah penelitian kepustakaan (Library research), yaitu penelitian yang menggunakan buku-buk sebagai sumber datanya. Metode pengumpulan daya yang digunakan dalam penelitian ini adalah metode dokumantasi. Sedangkan analisis yang digunakan dalam penelitian ini adalah analisis isi, yaitu suatu upaya yang dilakukan dalam rangka melihar dan menganalisis kerangka konseptual dari falsafah Astha Brata dan implikasinya terhadap kepemimpinan kepala sekolah dan guru. Metode analisis isi merupakan analisis ilmiah yang menekankan pada pesan atau isi yang dibangun secara sistematis dan objektif dan dengan metode ini diharapkan proses analisis akan menghasilkan pemahaman yang mendalam serta objektif terkait aktualisasi Astha Brata sebagai upaya membentuk profil Pelajar Pancasila melalui Sekolah Penggerak.

\section{HASIL DAN PEMBAHASAN Aktualisasi Nilai-nilai Kepemimpinan Astha Brata Pada Sekolah Penggerak}

Satuan pendidikan sebagai pelaksana program Sekolah Penggerak ditetapkan melalui mekanisme seleksi kepala satuan pendidikan (kepala sekolah) yang memiliki kepemimpinan pembelajaran (instructional leadership) dimana dalam Keputusan Menteri Pendidikan, Kebudayaan, Riset dan Teknologi Republik Indonesia Nomor 162/M/2021 tentang Program Sekolah Penggerak disebutkan bahwa kriteria seleksi Kepala sekolah berdasarkan model kompetensi kepemimpinan dengan kategori:

1. Mengembangkan diri dan orang lain

2. Memimpin peembelajaran

3. Memimpin manajemen satuan pendidikan, dan

4. Memimpin pengembangan satuan pendidikan

Dalam rangka mewujudkan sekolah yang berpusat pada murid maka Kepala Sekolah yang merupakan pimpinan pembelajaran di setiap satuan pendidikan yang menggerakan sekolah dengan cara berkolaborasi bersama pemangku kepentingan lainnya hal ini sesuai dengan watak laut atau samudra dimana kepala sekolah harus mampu menampung semua aspirasi serta bekerjasama dengan semua warga sekolah maupun dengan stakeholder. Kepala sekolah sepeerrti sifat bumi diharuskan siap mengabdikan diri serta dapat menjadikan pijakan setiap kegiatan dari satuan pendidikan yang dipimpinya serta teguh dan tidak berputus asa dalam memngadapi permasalahan yang akan muncul dari pelaksanaan sekolah penggerak.

Selain itu juga sekolah harus melakukan inovasi-inovasi yang diharapkan akan menghasilkan perubahan dalam berbagai aspek dalam rangka peningkatan kualitas guru mengajar serta siswa belajar untuk mewujudkan profil pelajar pancasila. Perubahan tersebut diantaranya meliputi tujuan dan visi guru mengajar, belief dan asumsi guru terhadap pengajaran serta strategi guru dalam mengajar agar lebih interaktif dan dialogis yang bisa dilakukan melaui diskusi dua arah antara guru dan siswa. Agar dapat menjadi kreatif dan inovatif maka setaip elemen dari sekolah penggerak harus melakuakan perubahan. Dalam melakukan inovasi-inovasi ini maka kepala sekolah harus bisa menjadi pedoman serta isnpirasi bagi semua warga sekolah hal ini sesuai dengan watak bintang yang berfungsi sebagai penujuk arah.

Peningkatan kualitas hasil belajar siswa yang meliputi karakter, literasi dan numerasi dapat tercapai jika terjadi perubahan dan inovasi yang dipimpin oleh kepala sekolah hal ini sesuai dengan watak matahari dimana kepala sekolah harus mampu memberikan dorongan energi kepada guru dan siswa agar dapat melakukan inovasi 
serta peruubahan agar tujuan bersama yaitu peningkatan kualitas belajar siswa serta profil pelajar pancasila tercapai.

Dalam upaya melaksanakan inovasi-inovasi dalam kurikulum merdeka belajar serta dalam sekolah penggerak meruapakan hal yang baru maka bukan tidak mungkin akan banyak tantangan serta hambatan yang dihadapi dalam kinerja seluruh anggota satuan pendidikan maka sesuai dengan watak api kepala sekolah harus mampu memberikan semangat kepada semua anggota satuan pendidikan cekatan serta tegas dan berani dalama mengambil setiap keputusan.

Sebagai sebuah kebijakan baru profil pelajar pancasila serta sekolah penggerak maka dalam perjalananya akan terdapat kendala bahkan pada tahap awal pelaksanannya terdapat perbedaan pemahaman yang diakibatkan belum adanya pemahaman yang sama tentang pelaksanaan sekolah penggerak oleh karena itu dalam kondisi seperti itu maka kepala sekolah seperti halnya sifat bulan yang dapat memberikan rasa aman menciptakan lingkungan kerja yang kondusif yang pada akhirnya dapat mengoptimalkan pekerjaan seluruh anggota satuan pendidikan.

Dalam melaksanakan program sekolah penggerak maka kepala sekolah sesuai dengan sifat air harus bisa secepatnya beradaptasi dengan menyesuaikan diri dengan berbagai perubahan baru dan juga mampu melihat potensi dan kebutuhan dari setiap warga sekolah. Selain itu juga harus mampu menganalisa permasalahan yang muncul secara aktual serta mampu mendengarkan masukan dari berbagai pihak hal ini sesuai dengan sifat angin.

\section{SIMPULAN}

Kepemimpinan kepala sekolah mempunyai andil yang besar dalam kesuksesan program sekolah penggerak yang akan mewujudkan profil pelajar pancasila. Kepemimpinan Astha Brata yang digambarkan dengan delapan sifat alam merupakan kesatuan konsep yang integral dimana delapan sifat dari alam tersebut harus menyatu dalam diri pemimpin. Dalam Astha Brata mengajarkan kepemimpinan kepala sekolah yang fleksibel seusai dengan tiap watak dari delapan sifat alam.

\section{DAFTAR PUSTAKA}

Abbas, S. (2014). Manajemen Perguruan Tinggi. Jakarta: Kencana

Ahmad Febri Kurniawan. (2019). "Falsafah Kepemimpinsn Pendidikan (Hasta Brata sebagai Basis Kepemimpinan Pendidikan" Rl'AYAH, Vol. 04, No. 02, Juli-Desember 2019

Hasudungan, Anju Nofarof, and Nur Fatah Abidin. (2020). "Independent Learning:Forming The Pancasila Learner Through Historical Learning In Senior High School." Seminar Nasional Pembelajaran Sejarah (SNPS UNS 2020), 3 (2): 34-42.

Kemdikbud. (2021). Pelaksanaan PPDB SMA Program Sekolah Penggerak (Modelpendaftaran dalam PPDB dan Strategi Komunikasi). Materi pada webinar Sekolah Penggerak, 7 Juni 2021.

Kemdikbud. (2021). Profil Pelajar Pancasila (Unit Modul Pelatihan Sekolah Penggerak). Materi pada Pelatihan Komite Pembelajaran Sekolah Penggerak, 10-21 Juni 2021.

Kemdikbud. (2021). Kerangka Kurikulum (Unit Modul Pelatihan Sekolah Penggerak). Materi pada Pelatihan Komite Pembelajaran Sekolah $\quad$ Penggerak, $10 \quad-21$ Juni 2021. 
SHEs: Conference Series 5 (1) (2022) 56- 62

Kemdikbud. (2021). Prinsip Pembelajaran dan Assesmen (Unit Modul Pelatihan Sekolah Penggerak). Materi pada Pelatihan Komite Pembelajaran Sekolah

Penggerak, 10 -21 Juni 2021.

Sudaryanto, Sudaryanto, Wahyu Widayati, and Risza Amalia. (2020). "Konsep

Merdeka Belajar-Kampus Merdeka Dan Aplikasinya Dalam Pendidikan Bahasa (Dan Sastra) Indonesia." Kode: Jurnal Bahasa, 9 (2): 78-93. https://doi.org/10.24114/kjb.v9i2.18379.

Sundari, A. (2015). "KEarifan LoKal Dalam Institusi PuBliK: Studi Gaya KEPEmimPinan Jawa HastaBrata Pada SEKolah MEnEngah Di KaBuPatEn

JEmBEr." LITERASI: Indonesian Journal of Humanities, 4 (2).

https://jurnal.unej.ac.id/index.php/LIT/article/view/6270.

Kepmendibud Nomor 162/M/2021 tentang Program Sekolah Penggerak. Diakses tanggal 20 September 2021 dari https://penggerak-simpkb.s3.ap-southeast 1.amazonaws.com/portal-programsekolahpenggerak/wp content/uploads/2021/07/14142514/Salinan-Distribusi-II-Kepmen-162 tentang-PSP.pdf

Direktorat Sekolah Menengah Atas, Dirjen PAUD, Dikdas, Dikmen (2020) Buku saku merdeka belajar : prinsip dan implementasi pada jenjang pendidikan SMA. Direktorat Sekolah Menengah Atas, Jakarta http://repositori.kemdikbud.go.id/id/eprint/20029 